\title{
mediação pedagógica e imaginação na educação infantil
}

\author{
adriana regina isler pereira leite ${ }^{1}$ \\ pontifícia universidade católica de campinas - brasil \\ maria silvia pinto de moura librandi da rocha ${ }^{2}$ \\ pontifícia universidade católica de campinas - brasil
}

resumo

As reflexões sobre as manifestações imaginativas das crianças e os modos pelos quais são/podem ser trabalhadas nos contextos educacionais têm grande importância porque delas podem derivar diversas contribuições para $\mathrm{o}$ trabalho pedagógico $\mathrm{e}$, consequentemente, para o desenvolvimento infantil. Neste campo, as seguintes perguntas são relevantes: o cotidiano organizado pelo educador para as crianças é rico e desafiador? Nele são feitos convites para as manifestações das crianças a respeito das rotinas, dos tempos e dos espaços instituídos? O educador é capaz de uma escuta sensível e um olhar atento a estas manifestações? $\mathrm{O}$ que as crianças produzem nas ações e interações que ali ocorrem vincula-se, de forma potente, à esfera da imaginação? Via de regra, as repostas a estas perguntas são negativas. Por esta razão, a turma junto a qual se desenvolveu a pesquisa e o trabalho pedagógico realizado por sua professora foram considerados campo e objeto de investigação instigantes por representarem formas atípicas de valorização da capacidade imaginativa das crianças. O objetivo do trabalho é identificar mediações na relação professor-crianças que sustentam, de maneiras diferenciadas, o desenvolvimento da imaginação (dentro de uma perspectiva Histórico-cultural), e realçar aspectos da estrutura do cotidiano educacional, priorizando possibilidades de escolha por parte das crianças como importante condição neste campo.

palavras-chave: imaginação; infância; práticas pedagógicas.

\section{la mediación pedagógica y la imaginación en educación infantil}

resumen

Reflexiones sobre las manifestaciones imaginativas de los niños y las formas en que están / se pueden trabajar en contextos educativos son muy importantes ya que pueden dar lugar a varias contribuciones a la labor pedagógica y en consecuencia para el desarrollo infantil. En este campo, las siguientes preguntas son relevantes: el diario organizado por el educador para los niños, es rico y desafiante? En ella se hacen invitaciones para las expresiones de los niños acerca de las rutinas, los tiempos y espacios establecido? El educador es capaz de una escucha sensible y una mirada hacia fuera para estos eventos? Lo que los niños producen en las acciones e interacciones que se producen no está vinculado, de forma potente, la imaginación de la esfera? Por regla general, las respuestas a estas preguntas son negativas. Por esta razón, el grupo con el que la investigación se llevó a cabo y el trabajo pedagógico realizado por su maestro se consideraron campo y objeto de investigación apasionante, ya que representan formas atípicas de recuperación de la capacidad imaginativa de los niños. El objetivo es identificar las mediaciones en la relación maestro-niño que apoyan formas diferenciadas, el desarrollo de la imaginación (dentro de un pesrspectiva histórico-cultural) y mejorar los aspectos de la estructura de la

\footnotetext{
${ }^{1}$ E-mail: dripleite@gmail.com

2 E-mail: silrocha@uol.com.br
} 
mediação pedagógica e imaginação na educação infantil

educación todos los días, dando prioridad de elección por los niños como una condición importante en este campo.

palabras clave: la imaginación; la infancia; prácticas pedagógicas.

\section{pedagogical mediation and imagination in early childhood education}

abstract

Reflections on the imaginative manifestations of children and the ways in which they are / can be worked out in educational contexts are of great importance because they can derive various contributions to pedagogical work and consequently to child development. In this field, the following questions are relevant: Is the daily routine organized by the educator for children rich and challenging? Are there invitations to the manifestations of the children regarding the routines, the times and the spaces instituted? Is the educator capable of a sensitive listening and an attentive look at these manifestations? What do children produce in the actions and interactions that occur there is linked, in a powerful way, to the sphere of the imagination? In general, the answers to these questions are negative. For this reason, the group that developed the research and the pedagogical work carried out by their teacher was considered an instigating field and object of investigation because they represent atypical forms of valuing the children's imaginative capacity. The purpose of this work is to identify mediations in the teacher-child relationship that support in different ways, the development of the imagination (within a historicalcultural perspective) and highlight aspects of the structure of daily education, prioritizing possibilities of choice by children as an important condition in this field.

keywords: imagination; childhood; pedagogical practices. 
mediação pedagógica e imaginação na educação infantil

\section{introdução}

Olhar crítico que vira pelo avesso a ordem das coisas, que subverte o sentido de uma história, que muda a direção de certas situações, exige que possamos conhecer nossas crianças, o que fazem, de que brincam, como inventam, de que falam. E que possam falar mais. Se concordamos que história e linguagem são dimensões fundamentais que conferem humanidade aos sujeitos sociais, se acreditamos que há uma história a ser contada porque há uma infância de homem, poderemos - compreendendo melhor nossas crianças - compreender melhor nossa época, nossa cultura, a barbárie e as possibilidades de transformação. Há que aprender com a criança a olhar e a virar pelo avesso, a subverter, a tocar o tambor no ritmo contrário não ao da banda militar, de tal maneira que as pessoas, em vez de gritar, obedecer ou marchar, comecem a bailar. (KRAMER, 2000, p.42-43)

Como pesquisadoras na área de Educação Infantil, destacamos o modo pelo qual são recorrentes, nos discursos e nas práticas educativas, as reflexões referentes às manifestações imaginativas das crianças e o movimento de incorporação de artes, jogos e brincadeiras nas diferentes esferas de ensino. É importante registrar que existem vários estudos, tais como os de Carvalho (2010), Neitzel (2012), Pires (2012) e Pontes (2013), que atravessam na área da arte e do brincar na instituição de Educação Infantil e que têm explorado aspectos importantes dessa esfera do desenvolvimento infantil, salientando a importância da interação entre parceiros, da capacidade de flexibilizar papéis, das formas de linguagem que emergem, da criatividade na elaboração sobre o vivido, do refinamento das significações sobre o mundo. Trata-se da relevância que essas esferas de atividade têm para o desenvolvimento da capacidade imaginativa e, consequentemente, do lugar que devem ocupar nas concepções e formas de trabalho na Educação Infantil.

Neste âmbito, é relevante uma maior compreensão em relação às ocorrências vinculadas às intervenções pedagógicas nas diferentes atividades e nos modos pelos quais se estrutura o cotidiano educacional, numa espécie de “exame geral" do lugar do professor e da criança, que é concretamente realizado na Educação Infantil. Na pesquisa da qual ora apresentamos os resultados, elegemos uma turma em que se tem desenvolvido um modo diferenciado de 
pensar e lidar com aspectos das manifestações imaginativas - trabalhando com enfoque na arte - e apresentando uma diversidade de práticas educativas que priorizam desejos, motivações e necessidades das crianças.

Por esta razão, a turma junto a qual se desenvolveu a pesquisa e o trabalho pedagógico realizado por sua professora foram considerados campo e objeto de investigação instigantes por representarem formas atípicas de valorização da capacidade imaginativa das crianças. $\mathrm{O}$ objetivo do trabalho é identificar mediações na relação professor-crianças que sustentam, de maneiras diferenciadas, o desenvolvimento da imaginação e realçar aspectos da estrutura do cotidiano educacional, priorizando possibilidades de escolha por parte das crianças como importante condição neste campo.

O texto está estruturado em dois grandes tópicos: primeiramente, apresentamos considerações teóricas sobre a constituição e o desenvolvimento da imaginação, destacando a importância das práticas pedagógicas nestes processos; após isso, apresentamos a pesquisa de campo; do conjunto total do material empírico, elegemos quatro cenários para serem analisados, buscando evidenciar possibilidades fecundas de trabalho pedagógico.

\title{
a imaginação segundo a teoria histórico-cultural
}

As questões em torno do processo imaginativo no desenvolvimento humano têm sido objeto de reflexão, na área acadêmica, com temas relativos à criatividade no âmbito educacional. Em geral, as brincadeiras têm sido eleitas como atividade central, a partir da qual debate-se como e porque os compromissos assumidos têm sido negligenciados. Corsino trata desta questão (2006, p.51):

\begin{abstract}
geralmente, a brincadeira é reservada a restritos espaços e tempos organizados na rotina escolar, como o recreio, os cantinhos de faz de conta, casinhas de boneca e/ou atividades dirigidas que a utilizam como recurso didático. Será que esses espaços e tempos institucionais têm garantido às crianças a possibilidade de imaginar, fantasiar, criar novas ordens, estabelecer laços de amizade, relações de sociabilidade e construir suas culturas próprias?
\end{abstract}

Há décadas, tanto no campo da Psicologia como no da Educação, tem-se buscado compreender as ações imaginativas dentro do âmbito educacional como 
fundamentais para o desenvolvimento da criança. Neste sentido, surgem diferentes modos de pensar e de trabalhar com a arte e o imaginário no espaço escolar; dentre eles o que sustenta basicamente a noção de imaginação como um processo espontâneo, produto natural da expressão infantil que se materializa no desenho, na brincadeira, na narração, e tem por objetivo a busca do prazer. Nesta perspectiva, costuma-se ressaltar que as atividades de desenho livre, massa de modelar, quando realizadas de forma supervisionada pela professora, tenderiam a restringir as possibilidades de criação, embora pudessem trazer "contribuições ao processo do aprendizado de procedimentos úteis à aquisição de habilidade motora e concentração para a aquisição da leitura e escrita" (CARVALHO, 2010, p.86).

Opondo-nos a esta concepção e buscando delinear o conceito de imaginação, reportamo-nos à esfera do brincar na modalidade do jogo imaginário como uma instância prototípica desse processo; fundamentamo-nos nas formulações de Vygotsky a esse respeito (1987a; 1987b; 1989). Nosso interesse não se restringe ao brincar, mas o tomamos, agora, como instância típica das manifestações imaginativas e que nos permite estender as interpretações sobre outras formas de atividades que envolvem essas manifestações. Para Vygotsky (1987a), no brincar e em outras atividades que envolvem a imaginação, a criança combina e cria novas imagens; os objetos passam a ter outras funções, fora daquilo que já está, culturalmente, determinado, do previsível. Na produção imaginária, ao longo do desenvolvimento, novas combinações do real vão se tornando possíveis; criar, frente aos significados já construídos; reelaborar acontecimentos vividos no cotidiano por meio da memória de experiências passadas e através da linguagem são algumas das mais importantes possibilidades de trabalho psíquico. Ao discutir a imaginação, esse autor aprofunda questões presentes neste processo, apontando quatro níveis da relação entre a imaginação e a realidade.

Em primeiro lugar, considera que é impossível criar algo novo sem se dispor de algo já existente. Logo, os elementos utilizados no processo criativo são obtidos nas experiências ocorridas anteriormente. A partir desses elementos, a criança reelabora-os e modifica-os, criando novas formas de combinação. Essa 
relação entre os elementos tomados da realidade para se constituir no processo imaginativo é proposta por Vygotsky (1987a, p.12) como sendo o primeiro vínculo entre a imaginação e a realidade: "as maiores fantasias não são mais que novas combinações dos mesmos elementos tomados, afinal de contas, da realidade, submetidos simplesmente a modificações ou re-elaborações em nossa imaginação".

A segunda relação apontada pelo autor está na capacidade de imaginação que possibilita a ampliação das experiências, de maneira que a criança pode se apoiar nas experiências vivenciadas por outras pessoas, transformando-as em suas. Nesse nível, a imaginação "converte-se em meio de ampliar a experiência do homem, ao ser capaz de imaginar o que não viu, podendo conceber baseado em relatos e descrições alheias e que não experienciou pessoalmente e diretamente" (VYGOTSKY, 1987a, p.20). Por exemplo, a criança pode imaginar-se esquiando na neve mesmo sem já ter esquiado alguma vez, com base somente nas descrições de outras pessoas, ou através de imagens presenciadas na mídia, condições essas que tornam possível construir no plano imaginário o que não foi diretamente experimentado.

Um terceiro modo de relacionar a imaginação e a realidade concerne à esfera afetiva. Por meio da imaginação, por exemplo, a criança é capaz de sentir medo ao ouvir um barulho diferente em sua casa e consegue projetar cenas do que pode ter causado o barulho. De acordo com o estado de ânimo, também se pode criar ideias, extraindo elementos da realidade e compondo-os numa nova instância. Assim, "todo sentimento, toda emoção pode se manifestar em determinadas imagens concordantes com ela, como se a emoção pudesse eleger impressões, ideias, imagens congruentes com o estado de ânimo que nos dominasse naquele instante". (VYGOTSKY, 1987a, p.21)

A última forma de relação está na direção imaginação-realidade. Vygotsky (1987a, p.24) argumenta que o "edifício erigido pela fantasia pode representar algo completamente novo, não existente na experiência do homem nem semelhante a nenhum outro objeto real". Isto é, o produto da imaginação pode ser algo 
completamente novo, dessemelhante de um objeto existente, e pode cristalizar-se, fazer parte do mundo, materializando-se e influindo nele. $\mathrm{O}$ produto da criação passa a compor a realidade, transformando-a.

Esta visão sobre as manifestações imaginativas propostas pela perspectiva Histórico-cultural não é predominante dentro da Psicologia. Nela há também concepções da produção imaginária como algo linear, relacionado à soma de experiências anteriores, explicando-a pelas "impressões acumuladas" e/ou como resultado da genialidade individual e natural de determinados sujeitos.

Cruz (2002) retoma a controvérsia, problematizada por Vigotski³, entre as posições idealistas e materialistas sobre o desenvolvimento da imaginação, quanto a esta ser ou não uma atividade consciente e quanto à relação existente entre a imaginação e as experiências acumuladas. O modo pelo qual as sensações ou impressões imediatas e acumuladas se transformam em imaginação não fica explicado nessas visões. Elas não dão conta de que se trata de uma forma de representação inteiramente nova; são novas imagens, novas combinações, ainda que constituídas a partir do já conhecido.

Como podemos depreender, definir "imaginação" é algo complexo. Conforme apontado por Góes (2000), quando falamos de ações imaginativas, é comum que nos reportemos a elaborações sobre o irreal, o inverossímil, o improvável, o transgressivo; de fato, essas possibilidades estão inscritas nesses modos de manifestações, mas não excluem (ao contrário, pressupõem) o real, o verossímil, o provável, o normativo, como se pode constatar nas brincadeiras de encenação de personagens.

A criatividade humana parte da experiência pessoal, do contexto históricocultural, e é ampliada pela imaginação, ou seja, é influenciada pela história, está relacionada, diretamente, com a riqueza de experiências vividas pelas crianças. A base para a imaginação está nas experiências acumuladas; por isso, quanto mais variadas e ricas forem, mais abundante será a fantasia; entretanto só com o

\footnotetext{
${ }^{3}$ Optamos por utilizar a grafia Vigotski, seguindo acordo brasileiro para menção ao autor, quando não se trata de trabalhos específicos. Entretanto, no caso de obras referenciadas, serão respeitadas as formas utilizadas nas respectivas edições.
} 
distanciamento do real, com a transformação do imediatamente percebido, pode ocorrer a reorganização de imagens e fatos vivenciados, caracterizando a capacidade criadora. Em síntese, "toda obra criadora constitui um processo histórico consecutivo donde cada nova forma se apoia nas precedentes". (VYGOTSKY, 1987a, p.37-38). Mas ultrapassa-as, podemos acrescentar.

Nessa perspectiva, a capacidade criativa humana está presente em inúmeras formas de atividade: entre elas a criação artística, que reflete e refrata a/em nossa vida; a criação científica que questiona e produz conhecimentos relativos às problemáticas da realidade do homem; e a técnica, que no seu fazer materializa as próprias condições da vida humana. Em suma, torna-se claro que essa capacidade não está divorciada da realidade e da cognição.

Retomando as questões da infância, as ações imaginativas expandem o campo da atividade, permitindo desprender-se das restrições da situação imediata, reelaborando significados em relação ao campo perceptual e, gradualmente, produzindo significados independentes de qualquer suporte tangível, através da ficção ou simulação. Neste sentido, poderíamos dizer que, de modo distinto do que é recorrente (tanto no senso comum como em algumas abordagens teóricas da Psicologia e da Pedagogia), de uma forma mais geral, as manifestações imaginativas para Vigotski são mais complexas, e que a alimentação destas é fundamental para o desenvolvimento infantil e humano.

Já no início do desenvolvimento podem-se observar atos criativos nas crianças, os quais envolvem formas de elaboração fundadas na imitação ativa ou reprodução do que vivenciam. "Desde os primeiros anos de sua infância encontramos processos criadores, que se refletem, sobretudo, em suas brincadeiras. O menino que cavalga sobre um pau e se imagina que monta a cavalo, a menina que brinca com sua boneca e se vê como mãe." (VYGOTSKY, 1987a, p.12)

As considerações trazidas nos levam a pensar nas práticas cotidianas em sala de aula, nas posturas do educador, em suas significações im/explícitas frente às manifestações imaginativas e, consequentemente, à arte. Dependendo das 
experiências organizadas no contexto escolar e das mediações realizadas pelos educadores, abrem-se inúmeras possibilidades a estas manifestações, permitindo às crianças exercerem e desenvolverem sua criatividade.

Nos trabalhos que temos realizado junto aos professores e profissionais da área de educação infantil vale a pena destacar, novamente, que as reflexões no que diz respeito às manifestações imaginativas das crianças e o movimento de incorporação de jogos e brincadeiras nas diferentes esferas de ensino têm sido realçados. Essa tendência vem sendo reforçada em documentos oficiais publicados com intuito de orientar os sistemas educacionais, desde os "Referenciais Curriculares Nacionais de Educação Infantil", documento emitido pelo MEC em 1998-1999 (BRASIL, 1998), até os documentos mais atuais (BRASIL, 2009; 2012).

Como Germanos (2001) já discutia, esses referenciais ressaltam a importância do brincar para o desenvolvimento infantil. Encorajam o professor a favorecer espaços físicos e materiais para as brincadeiras, a incluí-las de forma regular no trabalho cotidiano, a utilizar-se desses momentos para observar o desenvolvimento das crianças em grupo e/ou individualmente e, ainda, a tomar essa atividade como um recurso didático, como estratégia para a atuação em todas as áreas de conhecimento.

É importante ressaltar, porém, a existência de uma série de promessas, méritos, lacunas e contradições nas orientações oficiais. Terciotti (2001) já evidenciava problemas na concepção e viabilização das iniciativas sugeridas pela documentação, que toma a forma de referenciais, diretrizes e programas de desenvolvimento profissional do professor. Esses problemas fazem parte de um cenário mais amplo de indagações, conforme discutem, por exemplo, Palhares e Martinez (1999), Rocha (2005), Abramowicz (2009), Leite (2012), Faria et al (2013), Arce (2007).

A partir destas considerações e de estudos realizados referentes à atuação de educadores infantis frente ao brincar (LEITE, 2004), em escolas de Educação Infantil que apresentavam uma perspectiva de trabalho convencional e sua prioridade era o conteúdo, com uma concepção de ensino-aprendizagem 
fundamentada no investimento na transmissão-recepção e na "estimulação de uma prontidão" para níveis superiores que se relacionam às habilidades tidas como mais importantes nas escolas, visando minimizar as (ao menos supostas) defasagens das crianças nos aspectos cognitivos e motores. Destaca a autora, três perspectivas presentes nas visões destas educadoras, que, por vezes, são conciliadas ou alternadas na sala de aula: (1) a imaginação é prejudicial à elaboração do real, exige a cautela de evitar a ficção e a simulação, para que estas não interfiram na cognição e, em especial, nas atividades que visam à construção de conceitos de valor instrucional; (2) a imaginação é importante por ser natural da criança e deve-se conceder espaços para a ficção e simulação, porém preservando a prioridade do que pertence à ordem da cognição; (3) a imaginação é natural da criança, como na visão anterior, mas sua importância é instrumental, como meio e pretexto para ensinar o que é sério.

Devemos considerar que a relevância do trabalho a ser desenvolvido na Educação Infantil referente à arte e à imaginação, assumida nos documentos oficiais e nos Projetos Político Pedagógico, exige dos educadores modos de compreensão da arte, da imaginação, de pensar a e na criança, assim como na sua criatividade, capacidade de elaboração, o seu exercício de planejar e replanejar sua aula, até o exercício de imaginar, de experimentar junto com as crianças, compartilhando momentos e o que está por vir. Desta forma, podemos afirmar que o cotidiano na educação infantil é permeado tanto pelas políticas públicas, quanto pela realidade das instituições, pelas ações dos professores, pelo universo das realizações de novas elaborações culturais efetivadas pelas crianças, e pelas interações de todos esses fatores do dia a dia da escola, e que se manifestam nos espaços constituídos como: lugares de trocas, de expressão, de ampliação de experiências, de produção de conhecimento, de vivência de afetos e sentimentos, de conquistas e desenvolvimento das crianças, em que se constituem identidades e subjetividades. Isto posto, a seguir apresentamos a pesquisa realizada.

cenas do cotidiano: a imaginação nas artes de crianças da educação infantil Motivadas pelo fato de uma das autoras conhecer alguns trabalhos 
diferenciados, de uma escola da Rede Municipal de Ensino de Educação Infantil, interior de São Paulo, e em conversa com a direção desta unidade, consideramos a importância de estudar estas experiências inovadoras e de socializarmos outros modos de pensar a educação para e com as crianças. Buscamos observar as mediações da relação professora-criança nas práticas pedagógicas e suas possibilidades de contribuir com novos subsídios relativos ao desenvolvimento da imaginação infantil e ao papel das práticas pedagógicas. Para isso, realizamos uma pesquisa com vídeo-filmagens - a pesquisadora circulando, caminhando com a câmara pelos espaços conforme as atividades propostas pela professora se desenrolavam: na sala de encontro das crianças, no parque, na área verde, durante duas semanas cursivas, em uma turma com 22 crianças do jardim I (de 4 a 5 anos de idade). Já no primeiro dia da observação, a pesquisadora foi apresentada para as crianças pela professora, informando que estaria com elas filmando os trabalhos que eles iriam realizar, e que futuramente nós ajudaríamos a pensar trabalhos interessantes para fazer com elas.

As crianças frequentavam a escola em período integral. Porém, tinham uma professora para cada período. Optamos por realizar as observações no período matutino devido a informações obtidas sobre as práticas pedagógicas diferenciadas apresentadas pela professora deste turno, com trabalhos que priorizam a arte e as crianças, nas práticas educativas.

É importante salientar que o cotidiano das atividades propostas pela professora é bem flexível, não organizado em rotinas como frequentemente encontramos na Educação Infantil, com isso, as filmagens foram se tornando parte do cotidiano, e a pesquisadora interagindo com as crianças, na medida que, pediam: para olharem na câmara, para a pesquisadora auxiliarem a transportarem material, outras que pediam ajuda para subir nas árvores, algumas mostravam os suas as atividades que estavam fazendo, o seu corpo pintado de tinta, as próprias crianças incorporavam a pesquisadora nas propostas feita pela professora. $\mathrm{O}$ tempo de encontro da professora com as crianças é dinâmico; o próprio ato de fazer, de mediar, de acontecer aos poucos vai materializando as atividades, no 
mediação pedagógica e imaginação na educação infantil

próprio fluxo das relações das crianças com a professora e entre as próprias crianças; é com o tempo e no próprio tempo que a participação das crianças vai surgindo, e, aos poucos, as práticas pedagógicas vão tomando forma, de tal modo que conteúdos - um desenho, uma pintura, um recorte, uma colagem, uma música, uma dança vão surgindo. Feitas as observações, foram selecionadas das filmagens algumas situações, fragmentos de um dia, que convergiam aos objetivos do estudo para suas respectivas análises. Estes fragmentos foram transcritos e são apresentados a seguir, na forma de cenários, para que seja possível uma visualização mais ampla do contexto.

\section{cenário1:}

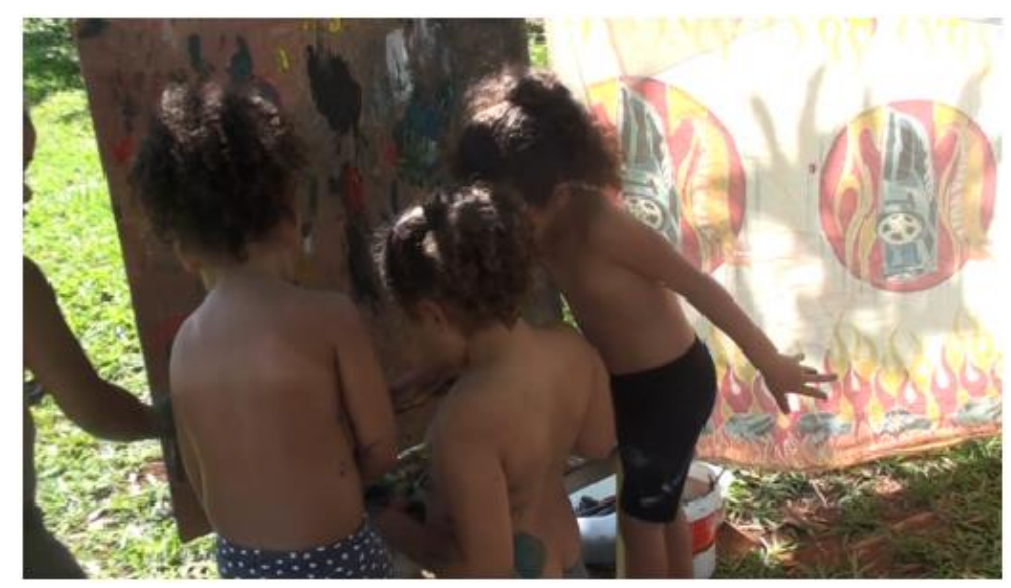

Figura 01 - Tela no acampamento

Fonte: Arquivo das pesquisadoras

Neste dia, a professora inicia a jornada chamando as crianças para que sentem-se ao seu redor, sem exigência de que formem uma roda, como é comum em turmas da Educação Infantil. Algumas crianças falam de diferentes assuntos, outras relembram situações vivenciadas, $e$ assim, uma palavra puxa outra, um assunto desencadeia outros, entrelaçando um fluxo e produzindo uma dinâmica interativa. Em um determinado momento a professora diz:

Profa: Agora eu vou falar uma coisa. A professora separou uns tecidos e nós vamos fazer um acampamento lá fora.

Aos poucos a roda vai se desfazendo e a professora finaliza com a seguinte fala:

Profa: Nós vamos levar o painel lá fora, para quem quiser ajudar a terminar de pintar o painel. O painel é um pedaço de madeirite, em que as crianças já haviam passado cola e espalhado areia por cima, dando uma outra textura à madeira; essa atividade foi realizada em um outro dia e o material estava guardado em um canto da sala.

Em seguida se organizaram em uma grande área externa da escola, em que havia árvores e gramado. Algumas crianças auxiliam a professora a levar os materiais que irão utilizar para a pintura do painel, outras escolhem brinquedos, sucatas, papéis que querem levar para brincarem. 
Algumas crianças recortam papéis em um pote, outras correm pela área, outras ainda voltam para sala para buscar outros materiais. Enquanto a professora e algumas crianças organizam o acampamento embaixo de algumas árvores, amarram lençóis na árvore e colocam um edredom no chão. A professora ouvindo as crianças anunciarem a palavra tesoura diz:

Profa.: Quem pegou as tesouras fica responsável por guardar!!

Jorge e Luísa mexem no pote de pincéis, Luísa pede para Jorge não abrir.

Carlos se aproxima das crianças que estavam brincando, embaixo de uma árvore, espaço designado como um lugar legal para recortarem papéis, e com uma tesoura na mão, pergunta:

Carlos: Peguei uma tesoura já. E agora o que é para eu fazer?

Sandra: Cortar, só!!!

Carlos: Cadê o papel?

Sandra: Assim. [mostrando como corta]

Alguma criança diz: Eu corto o tomate!!!

Carlos: Cadê? Eu não vou cortar??

Sandra: Sim, né!!! Olha o papel!

Criança: Tá cortando esse papel?

Sandra: Pra fazer a comida.

[...]

Marcelo: Mamãeee, tô com fome. [dirigindo-se à Sandra]

[...]

Sandra: Cadê uma colher para mexer?? [pega uma caneta e faz gestos de quem usa uma colher] Mexe um pouquinho!! [mexe os papéis picados que estão em um pote de sorvete] e diz:

Sandra: Precisa de água pra mexer!!!!

Carlos: Água?

Marcelo: Não. É no arroz que põe água!

[...]

Sandra: Acho que isso é sopa!!!!

[...]

Carlos: Quem inventou essa brincadeira??

Enquanto isso, outras crianças se aproximam da professora, para pintarem o painel. Com o seu consentimento, algumas crianças tiram a camiseta para não sujar de tinta.

Lúcio, Jorge e Elsa pegam os potes de tinta e começam a abrir.

Sandra: [pergunta à professora]: Vai pintar, Pro?

A professora, respondendo à Sandra, diz:

Profa.: Espera um pouquinho, um grupo de cada vez. Pode ser?

A professora aproxima-se do painel com um pincel com tinta, e percebendo que algumas crianças carregavam o pincel com muita tinta, diz:

Profa.: Um pouquinho de cada vez, vamos tentar pintar sem misturar as cores. Se for misturar as cores vai precisar de um potinho separado, pega ...

Lúcio e Jorge pintam o painel, pintam a barriga. Ester pinta as unhas. E outras crianças se aproximam do painel e os meninos saem brincando com o corpo pintado: barriga, braço e mão.

Sandra: Eu vou pintar de azul.

Luana: Branco e vermelho [mistura as cores no pincel].

Marcelo: Deixa eu ver, preeeto [grita].

A professora se aproxima de Marcelo que estava pegando um pincel vermelho para colocar em um pote de tinta preta.

Profa.: Olha aqui, oh!! Você está usando pincel vermelho!! Olha Marcelo... [e Marcelo continua o que estava fazendo]

Luana: Oh, ohhh gente! Branco com... [pausa] Olha amiga! Amiga, branco com... [pausa] Olha Sandra! Sandra, branco com vermelho forma rooosa, olha. Olha, Sandra!

Sandra: [levanta a cabeça, olha na direção de Luana]: Que legal!!!

No transcorrer da atividade, observamos que algumas crianças que querem pintar se aproximam do painel, pegam pincéis e começam a pintar; outras vão saindo. A professora permite que misturem as tintas. Algumas crianças carimbam a sua mão com tinta no painel; a professora intervém alertando-as no sentido de que devem ter cuidado, quando forem carimbar, para não derrubar o painel com a força das mãos, e, também, solicita que as crianças tomem 
cuidado para não pintarem por cima do local que já foi pintado pelo colega. Pede, por fim, para não passarem o pincel muito forte para não retirarem a areia que foi colada. Mostra, com um pincel, como preencher os espaços que estão em branco.

Neste cenário com tintas, muitas crianças acabaram se pintando com as próprias mãos ou com pincéis, e depois começaram a correr pelo gramado brincando de se pegarem, pois eram monstros. A professora legitima estas ações simbólicas.

Profa.: O monstro vai te pegar...

Ao mesmo tempo, algumas crianças estão em cima da árvore, outras brincando de pega-pega, outras brincando com galho de árvore como se fosse uma espada.

Crianças correm, pulam, dançam; com as mãos, dedos, lápis, pincéis e tintas, desenham; com tesouras e colas recortam e colam entre as muitas outras ferramentas a que têm acesso. Exploram papéis, paredes, objetos de diferentes tamanhos, formatos e texturas, e até mesmo seu próprio corpo e de seus bonecos. Descobrem linhas, formas, cores, volume. Crianças ativas, interativas, exploradoras, produtoras de sentidos.

As possibilidades de criação imaginativa se instauram nas três atividades principais que se desenrolam. As sucessivas enunciações "cortar, só!", "eu corto o tomate!", "pra fazer a comida" permitem-nos flagrar a construção de uma brincadeira de casinha, nucleada pelo preparo de uma refeição que pode ser arroz ou sopa, em que pedaços de papel transformam-se em alimentos, um pote de sorvete vira panela, uma caneta vira colher e, ao menos para Marcelo, Sandra transforma-se em mãe. A riqueza das interações permite-nos dizer que a pergunta de Carlos, sobre "Quem inventou essa brincadeira??", não pode ser respondida apontando-se uma das crianças; trata-se de uma produção co-autoral, em que a ação e os dizeres de um sugere caminhos para as produções de sentido dos outros participantes deste pequeno grupo.

Esta mesma característica de co-autoria se faz presente em todo o cenário, quando focalizamos as ações das crianças e as mediações da professora. Às propostas de levar o painel para continuidade de sua pintura e os tecidos e edredom para a construção de um acampamento, as crianças incorporam outras ideias. Decidem, com autonomia, levarem tesouras, papeis brinquedos e sucatas. Entretanto, devemos notar que esta autonomia não é plena, pois há certas regras que precisam ser observadas no uso dos materiais e cabe à professora ressaltá-las: o respeito à produção dos colegas, o controle sobre a própria força para carimbar 
as mãos, mas não derrubar o suporte, o controle do pincel para não retirar a areia, o uso de potes adicionais para a mistura de cores... Esta última regra é parcialmente seguida, mas a professora parece perceber que pequenas infrações também fazem parte do cotidiano de trabalho na Educação Infantil, considerando que a capacidade de regulação do próprio comportamento ainda é um processo em construção, que compete com ações mais impulsivas. As mediações da professora, lembrando em que condições as tintas podem ser misturadas, parecenos produzir efeitos no comportamento de Luana que acompanha suas ações de mesclar tintas narrando o que está fazendo: "Branco e vermelho"; ou seja, não se trata de uma mistura fortuita, o que lhe permite observar o resultado com surpresa maravilhada e a motivar-se para partilhá-lo com Sandra. Parece-nos bastante provável que a regra para mistura de tintas será seguida de forma mais regular por Luana. Não, simplesmente, porque a professora manda, mas porque, desta forma, os resultados surpreendentes poderão ser melhores apreciados.

Por fim, acompanhamos o movimento de transformação de ações exploratórias com o material em ações simbólicas no caso das pinturas dos corpos. A condição propícia advém de uma solicitação das crianças para tirarem as camisetas, para não sujá-las. Gradualmente, os pincéis vão encontrando os corpos como suportes para a pintura e os resultados permitem às crianças assumirem o papel de monstros, legitimado pela professora.

A Educação Infantil é um espaço que permite que o educador abra um leque de alternativas para as crianças, incentivando-as e contribuindo para ações diversificadas, não as restringindo a momentos rotineiros e com padronizações do conhecimento.

A professora, por sua vez, tem a possibilidade de atuar como mediadora e mobilizadora, de ampliar a capacidade da criança e juntamente a isto de auxiliá-la a produzir sentidos sobre o mundo, de recriar o já existente. Mas

\footnotetext{
para isso, é necessário levar em conta o diálogo com a expressividade das crianças, o incentivo às suas capacidades de criar cenas, narrativas (com vários suportes), invenção de situações, soluções inusitadas para as questões que emergem no coletivo, permitindo-lhes prosseguir (GUIMARÃES, 2006, p.69).
} 
Lembrando que a criatividade humana é ampliada pela imaginação, imaginação que está relacionada diretamente com a riqueza de experiências vividas pelas crianças, ressaltamos que este espaço de possibilidades que o educador oferece e da forma com que é proporcionado às crianças - trilhando caminhos dos interesses, do olhar para a criança - faz com que estas tenham experiências das mais variadas e mais ricas, contribuindo, assim, para o desenvolvimento da imaginação.

Vigotski nos aponta que as manifestações imaginativas são mais complexas nos adultos, devido à amplitude de conhecimentos que têm da realidade, ao contrário do que comumente pensamos, o que não significa dizer que este autor subestima estas manifestações na criança. Para ele, a imaginação na criança, "não é mais rica, senão mais pobre que do adulto; no processo de crescimento se desenvolve também sua imaginação que é alcançada somente na idade adulta" (VYGOTSKY, 1987a, p.40). Entretanto, esta afirmação não deve ser tomada como algo que inexoravelmente ocorrerá. Para compreendê-la deve-se levar em conta o tipo de experiências que vão sendo propiciadas para cada sujeito. Sendo assim, é possível conjecturar que as crianças que participam desta turma podem ser capazes de ações imaginativas mais ricas e inovadoras do que adultos que, nas condições contemporâneas de escolarização e vida, de empobrecimento das experiências, são instados, sistematicamente, a reproduzirem e não a criarem.

\section{cenário 2:}

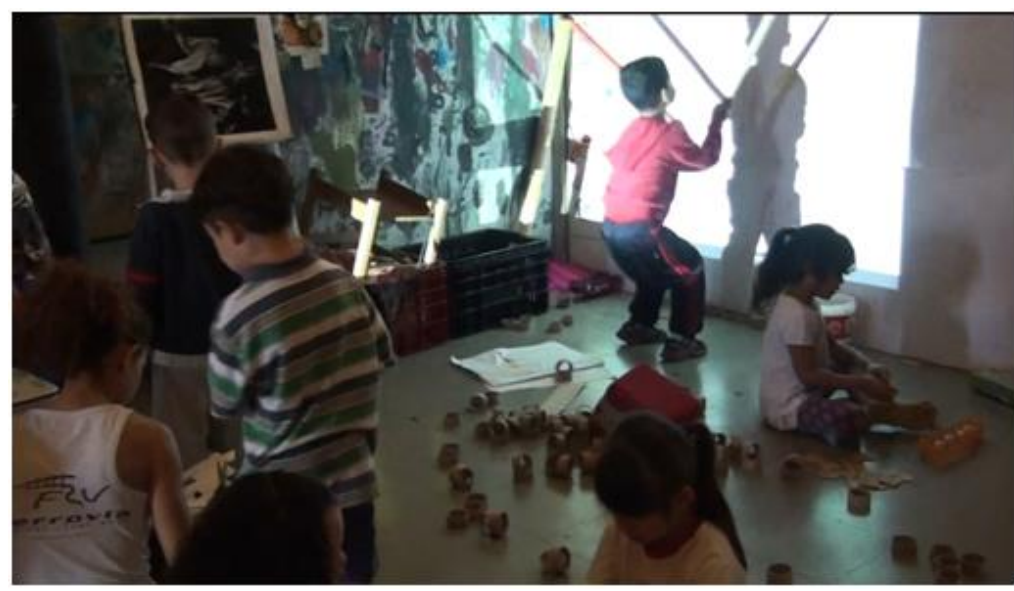


Figura 02 - Projetor

Fonte: Arquivo das pesquisadoras

Neste dia, a professora fixa várias cartolinas brancas em uma das paredes da sala de aula e monta um painel branco; em seguida, instala um aparelho de projetor de imagem, para projetar apenas a luz no painel. Antes de ligar o aparelho, uma das crianças pergunta à professora:

Criança: Que é isso Pro? Que é isso Pro?

Marcelo: É um filme!!

Profa.: É um filme???

Crianças: É um filme!!

Profa.: Vamos...

Algumas crianças estão em pé, outras sentadas na frente do painel, observam o que a professora está fazendo. Ao ligar o aparelho, aparece no painel uma tela branca; uma criança aproxima a sua mão no painel projetando assim sua sombra; na sequência, começa a brincar com os dois pedaços de madeira. Enquanto a professora finaliza a montagem do painel, outra criança também se aproxima e brinca com as mãos; aos poucos outros colegas entram na frente da luz e começam a brincar de sombra e/ou passam a mão diretamente sobre a cartolina. Durante a atividade, que vai ganhando adeptos, uma criança fala:

Criança: É a minha vez!!

Outra, atrás do foco de luz, dança para ver a sua sombra; outra balança as mãos. Enquanto isso, a professora continua arrumando o feixe de claridade, com o propósito de estar na altura das crianças e anunciando:

Profa.: Vocês já adivinharam o que eu quero fazer!!!

Ao terminar de focalizar a luz sobre todo painel, a professora pega um pedaço de papelão com alguns recortes; quando projetado parecia um pente e ela passa sobre a cabeça de uma das crianças como se estivesse penteando o cabelo e começa a brincar com as crianças. Caminhando, neste sentido, com a intenção de mostrar uma amplitude de objetos e formas de brincar com a projeção, pega algumas argolas de papelão e as projeta sobre o painel; diante disso as crianças começam a pegar argolas e a fazer o mesmo, e assim, a professora vai recorrendo a vários objetos existentes na sala e os utiliza no desenvolvimento da atividade. Com uma tiara de plumas, brinca que está fazendo cócegas; em outro momento coloca a tiara na cabeça de uma das meninas e pede para que ela fique quieta, e com um giz de cera faz o contorno da sombra projetada na cartolina, faz contorno da sombra da argola. Na sequência, a professora coloca música e algumas crianças vão dançar e brincar na frente do painel projetando, assim, suas sombras.

Neste dia, o projetor ficou ligado o tempo todo, com as luzes da sala apagadas e as janelas semi fechadas. As crianças puderam explorar esta situação de forma livre, sem orientações diretivas da professora. Algumas crianças passavam e brincavam de mímica com a sua própria sombra, outras ficavam muito próximas à luz, enquanto outras ficavam mais próximas das cartolinas fixadas na parede; várias procuravam um lugar para que sua sombra ou a sombra de algum objeto que tivessem em mãos ou sobre as cabeças fossem projetadas no painel; algumas aproveitaram a luz do projetor para brincarem no chão, outras utilizaram o painel branco para desenhar e outras utilizaram a luz para desenhar o contorno das sombras que as colegas iam projetando; em certos momentos, uma ou outra criança brincava de ficar bem próxima ao foco do projetor e, então, escurecia a sala de aula; os colegas reagiam a isso, perguntando: Quem apagou a luz?

Podemos notar que neste cenário, com ações sutis, a professora oferece múltiplas possibilidades de exploração de recursos diferenciados. A sala iluminada com a luz do projetor é uma outra sala. As crianças usufruem deste espaço, cada uma do seu modo: ora brincando com a luz, ora utilizando-a para brincarem, desenharem. As possibilidades de experienciarem a luz do projetor 
para brincarem de sombra (com seus corpos e objetos) instituem possibilidades de imaginarem, de fantasiarem, de criarem.

Entretanto, como também apontado em Rocha (2014, p. 235)

a simplicidade de trabalhos desse tipo (ou similares), entretanto, é apenas aparente; para o seu desenvolvimento é imprescindível contar com (pelo menos) duas garantias: a valorização do processo imaginativo e a disponibilidade de tempo para o planejamento diário das atividades a serem desenvolvidas com as crianças.

No contexto destes cenários, a professora institui condições profícuas para as manifestações imaginativas na infância, como espaços potentes e relevantes para processos de desenvolvimento e, sendo assim, constrói uma perspectiva de trabalhos pedagógicos diferenciados, nos quais se prioriza a criança, a arte e a imaginação, ampliando o conhecimento no que diz respeito às manifestações imaginativas. Algumas de suas ações se tornam modelos incorporados pelas crianças: a projeção da sombra de objetos variados, o contorno de corpos e coisas. Outras, tais como as ações simbólicas de pentear e a de fazer cócegas, não têm o mesmo efeito. E é importante que seja assim, pois na trama das experiências que se deseja que impregnem a imaginação há que se resguardar as apropriações idiossincráticas de cada um que delas participe.

\section{cenário 3:}

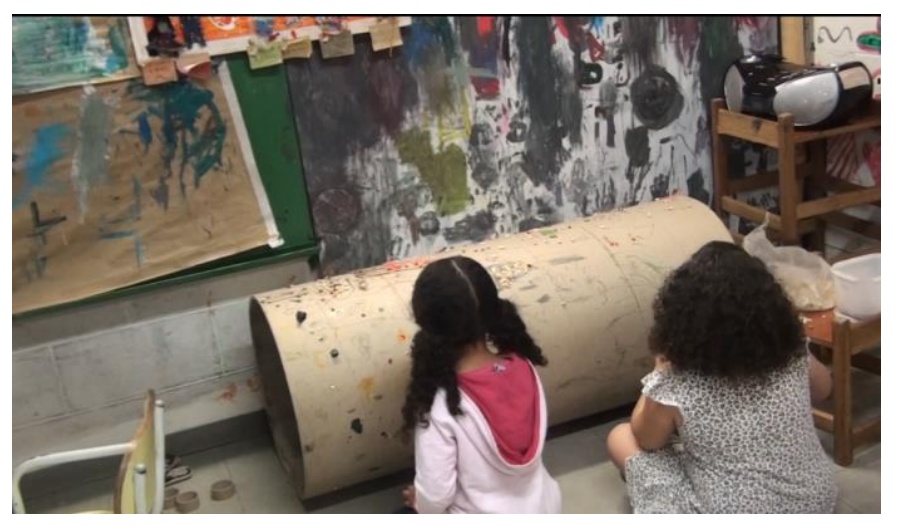

Figura 03 - Farol

Fonte: Arquivo das pesquisadoras

Em uma das conversas com a professora, ela nos explica que estavam fazendo uma atividade em que recortavam gravuras de revista e que Marcos apresentou uma gravura de um farol. Como já tinham em sala um rolo de papelão grosso, largo e comprido, maior que as crianças, a professora compartilha com elas a ideia de construir um farol, utilizando este rolo. 
Durante o período de observação a professora ofereceu três vezes oportunidades de produzirem o farol, sem seguir uma rotina rígida. A professora colocava-o deitado no chão da sala, encostado em uma das paredes, sempre anunciando que o farol estaria disponível para quem quisesse preenchê-lo; juntamente a ele, disponibilizava diversos tipos de grãos, miçangas e lantejoulas. O registro seguinte apresenta trechos das vezes em que o farol foi construído:

As crianças se aproximam do farol, cada qual procura um tubo de cola, escolhem o objeto que desejam colar e o colam; em momentos em que a quantidade de cola é excessiva, a professora aproxima-se da criança e a orienta sobre o uso do tubo e sugere que pode aproveitar o local em que ficou a cola escorrida para colocar outras pecinhas. Algumas crianças pegam pedaços de barbante que estão sobre a mesa, utilizado pela professora em outra atividade (no auxílio de confecção de máscaras), e colam sobre o tubo. Em um dos dias em que o farol foi disponibilizado, uma criança passou um grande período tentando colar feijões; eles escorregavam, mas com muita paciência e persistência, conseguiu colar diversos feijöes. Ao mesmo tempo, alguns colegas, sozinhos ou acompanhados, entravam no tubo com brinquedos e, consequentemente, o tubo se mexia (rolava um pouco); nestas ocasiões, a professora falava para as crianças que estavam dentro do tubo para tomarem cuidado; em certo momento, apoiou uma cadeira em cada ponta do tubo para que ele não rolasse, e as crianças continuaram a brincar, mesmo com amigos colocando objetos.

Paralelamente a esta atividade, as crianças brincam com bonecas, carrinhos, pedaços de madeira, argolas de papelão, peça de jogos, recortam papéis, constroem espadas de papel. A professora possibilita outras atividades como: (1) fixa com fita crepe um pedaço grande de papel pardo, no chão, onde algumas crianças desenham com giz de cera, cada um em um cantinho; (2) fixa no chão, em outro canto da sala, uma folha de papel pardo com um desenho de estacionamento de carros e algumas vias, elaborado por ela, e para ali as crianças levam carrinho, blocos de madeira, alguns animais e brincam em grupo.

Durante todo o período de observação, as crianças circulam pelos espaços da sala e também utilizam uma área externa, a que somente esta sala tem acesso, para correrem e brincarem; a professora também circula pelo espaço, sempre interagindo com elas, muitas vezes oferecendo outras possibilidades de brincar ou mesmo auxiliando-as nas confecções de espadas e do farol.

Como em outros trabalhos propostos, nem todas as crianças participam das mesmas atividades. Mas, na maior parte das vezes, elas aceitam o convite da professora e, aos poucos, a curiosidade e o desejo vão se intensificando e as interações se multiplicam, como é o caso da construção do farol, feita por fragmentos, em detalhes, com o olhar e com o toque de cada criança, sem preocupação com uma estética formal. A professora trabalha, portanto, na contramão do que registra Pontes:

a padronização e a homogeneização, a produção das crianças era orientada para responder ao desejo do professor e, embora afirmasse estar atento ao processo criativo das crianças, buscava padrões estéticos 
em que o belo/bom eram desejável como resultado final (PONTES, 2013, p.48).

Destacamos aqui o modo pelo qual a professora lida com o tempo: num primeiro momento é o tempo de apresentar, de oferecer os materiais às crianças, seguido por um tempo em que lhes permite conhecê-los, familiarizarem-se com ele; a professora respeita o tempo do desejo de cada um, no sentido de realizar ou não a atividade; por fim, o tempo de duração para executá-la é decidido por cada criança. Esta atividade ocorreu em vários dias, dias aleatórios, e ainda não havia sido encerrada quando deixamos o campo, pois é um trabalho longo e não existe urgência para completá-lo; caso houvesse, as crianças não dariam conta em fazêlo; por isso, disponibilizar, concomitantemente, outras atividades em diversos dias, é um procedimento bastante interessante para que o prazer na produção não se transforme em aceleração do ritmo para cumprir um cronograma rígido.

Outro ponto importante neste cenário é que nem sempre as proposições da professora são acatadas pelas crianças da mesma forma; ao invés de lidar com o rolo como um futuro farol, as crianças entram nele para brincar, transformando-o em um túnel, em um esconderijo; esta proposta foi aceita pela professora e, ao colocar cadeiras de apoio, cria condições para que as duas atividades sejam viáveis; o seu consentimento nos mostra a oportunidade que as crianças têm de explorar os objetos que as rodeiam, e ampliar as possibilidades de conhecimento.

Atividades como a do farol, da pintura do painel ao ar livre e a das sombras do projetor nos mostram diferentes condições que a professora possibilita às crianças para agirem, pensarem, produzirem arte. A professora está sempre aberta a outras atividades e a propostas das crianças, lembrando que elas não vivenciam o tempo todo os mesmos interesses, desejos; nem no mesmo tempo. Brincam de acordo com aquilo que lhes agrada, com o que são capazes de fazer, ampliando, gradativamente, não só a sua capacidade de entender sua expressão e suas possibilidades de transformações na cultura. 


\section{cenário 4:}
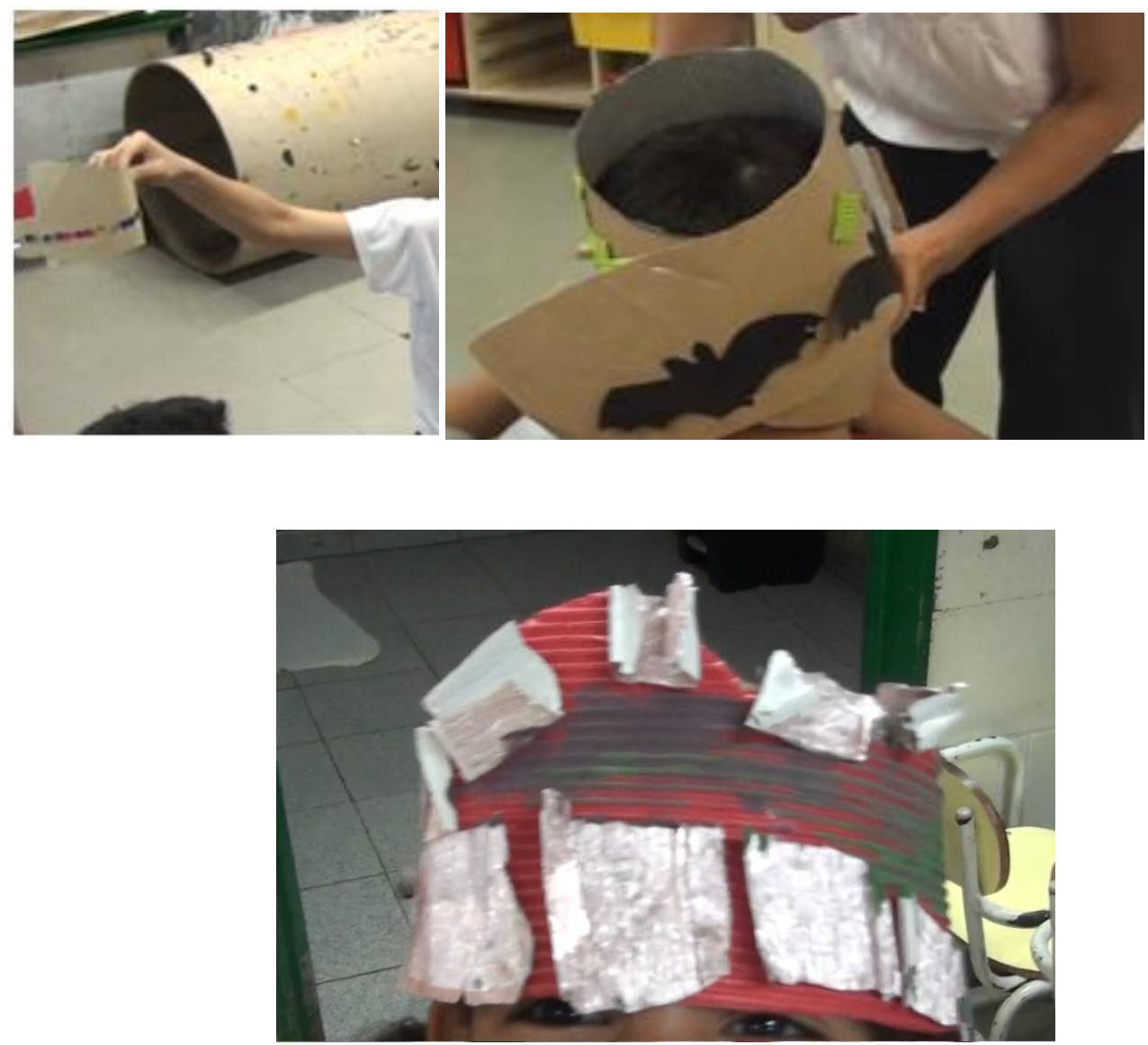

Figuras 04, 05 e 06 - Coroas.

Fonte: Arquivo das pesquisadoras

Neste dia, a professora traz uma folha grande desenhada, senta com as crianças no chão, e comenta:

Profa: Vocês lembram da estória que vocês desenharam?

Abre a folha e algumas crianças começam a recontar a estória desenhada por eles, juntamente com a professora. Logo em seguida, a professora propõe que façam roupas e máscaras dos personagens da estória; salienta que podem escolher qual elas queiram. Aqueles que se interessaram pela proposta partem para a confecção de suas roupas, coroas, espadas e máscaras. Gradualmente, outras crianças começam a se envolver na atividade. A professora vai auxiliando, dando dicas sobre como fazer a máscara: ora orienta as crianças a desenharem, primeiramente no papel crepom, duas linhas na largura da máscara, ora mostra o modelo dos amigos, ora indica como traçar; depois dá instruções para que elas recortem na linha; cada uma vai traçando e recortando do seu modo, algumas com mais facilidade, outras com menos. Depois retornam à professora para fazer o contorno para abertura dos olhos; mais tarde, novamente a procuram para fixar as máscaras em seus rostos.

Quanto às espadas, as crianças pegaram um rolo de papel crepom metalizado, passaram várias vezes uma fita adesiva transparente, para obter uma parte mais firme onde apoiariam as mãos. Depois colocaram as máscaras, pegaram as espadas e foram brincar de luta. Alguns voltavam e auxiliavam colegas na confecção da espada; outros que tiveram dificuldade de enrolar a fita, pediram ajuda para a professora.

Laís fez uma saia e depois uma blusa de papel crepom e a professora a auxilia, fixando o barbante para amarrar as peças no seu corpo, enquanto algumas meninas picam pedaços de papel e colam em um barbante para fazerem colares e pulseiras. Laís observa que um menino está com uma coroa, pede para professora fazerthe uma; a professora a orienta, ao invés de fazer por ela. Após terminar, Laís passa a manhã vestida com a roupa e a coroa; ao saírem para o almoço, pede para professora se poderia ir com as peças; a professora consente.

Cada criança cria a sua máscara, sua coroa compondo formatos diferenciados de acordo com os recortes que 
fazem e personalizam-nas conforme o material que usam: algumas colam lantejoulas, outras utilizam papel crepom metalizado; outra recorta tão pequeno que não serve em seu rosto; quando isso ocorre, a professora convida a criança para fazer outra. A confecção das máscaras retorna num outro dia, pois a professora pega as que algumas crianças não haviam terminado e as chama para fixar o elástico.

Como de costume, deixa os materiais que as crianças fizeram expostos na sala o que permite, por exemplo, que Lúcio pegue sua máscara para acrescentar mais papéis e que algumas crianças comecem a confeccionar outras também. O resultado final das produções é extremamente diversificado.

Este contexto é bastante frutífero para ilustrar como é possível a articulação de distintas atividades imaginativas: a narrativa, o desenho, a produção de artefatos simbólicos e as brincadeiras de faz de conta. E, assim, vai sendo produzida uma diversidade de objetos (máscaras, colares, roupas, espadas), ricos em detalhes e singulares em sua forma final, como apresentado nas imagens das máscaras (figuras 04, 05 e 06). Importante destacar que a predominante liberdade de ação das crianças sustenta-se nas mediações da professora, que reorganiza os pedaços de papel recortados pelas crianças, para transformá-los em uma máscara, auxilia-as em aspectos técnicos, até a sua finalização, com a colagem dos adereços. Assim, a motricidade humana vai se constituindo e se desenvolvendo; porém, é importante ressaltar que este desenvolvimento está a serviço das ideias, do planejamento, da representação.

A dinâmica de trabalho, portanto, é bastante distinta das rotinas mais comuns em turmas de Educação Infantil, nas quais as atividades costumam ser realizadas com fins em si próprias, desconectadas de uma significação mais ampla para as crianças, em um tempo de duração definido pelas professoras, e não costumam ser prolongadas por vários dias. A possibilidade de retornar ao que foi produzido, ressignificar os materiais e as produções, viver por dentro a história através do uso daquilo que criaram, vai fecundando as experiências que se tornam matéria prima para a imaginação, como propõe Vigotski.

Importante ressaltar que no cotidiano da turma observada, a última forma de relação entre imaginação e realidade - a materialização daquilo que se imagina - ocorre também com distintas temporalidades: ora como resultado de um trabalho processual e com uma permanência maior (como é o caso do painel e do farol, por exemplo), ora como resultado tão fugaz quanto a duração da luz do 
projetor, que permite a criação de milhares de sombras (como é o caso do segundo cenário apresentado), que logo desaparecem. Temos aqui um importante aspecto a ser observado na educação das crianças: o de cuidar da qualidade das experiências e não apenas de seu suceder quantitativo.

Nestes cenários registramos o quanto o trabalho da professora é um fluxo contínuo, em que necessita estar atenta, ter escuta e olhar sensíveis ao que as crianças sinalizam e/ou demandam explicitamente; de fato, não é nada simples ter que planejar e replanejar cada dia de trabalho e a cada ponto de inflexão nas produções, oriundos da participação ininterrupta das crianças nas atividades que vão sendo materializadas. No cotidiano desta turma vemos, com clareza, que as práticas pedagógicas constituem-se pelo

\section{incansável trabalho de inventar e planejar, a cada dia, como viabilizar, de maneira mais efetiva, o acesso das crianças ao conhecimento produzido e sua participação na produção histórico-cultural. Podemos aqui pensar na própria atividade pedagógica como atividade criadora (SMOLKA, 2009, p. 23).}

A amplitude de possibilidades oferecidas pela professora, sem uma preocupação em direcionar, de modo estrito, os trabalhos, mas sim dando suportes, auxiliando, apontando modos plurais de uso de materiais e de produção repercute no envolvimento das crianças e no estabelecimento de relação autoral com o que fazem.

Os contextos oferecidos são desafiadores, criativos, nos quais são valorizadas atividades que ampliam as experiências e o universo cultural, que aguçam a curiosidade, a capacidade de pensar, de decidir, de criar, de imaginar, de expressar. São momentos que as crianças dão sentido ao mundo, ao seu modo, produzem história, apropriam-se da cultura, ao mesmo tempo em que a transformam, experimentam e fazem arte.

A professora com suas propostas convida as crianças à ação e à imaginação; não tem uma atuação normativa, ou seja, não determina, na maior parte das vezes o quê e como devem realizar as atividades; podemos dizer que ela atua, orientando-as, quase como uma cenógrafa, possibilitando as cenas que serão também recriadas pelas crianças, o que faz com que elas possam ser sustentadas, ampliadas ou não, em tempos singulares de cada criança. 


\section{considerações finais}

Os planejamentos detalhados e a organização precisa da rotina no cotidiano da educação infantil podem, muitas vezes, ficar acima dos princípios pedagógicos que se tem como meta, quando a lógica de eficiência é imposta à instituição e ao professor, em decorrência. A fragmentação da prática pedagógica, a desconexão entre as diretrizes pedagógicas e aquilo que é efetivamente realizado é um problema antigo e discutido nas pesquisas em educação ainda hoje (CARVALHO, 2010, p.38).

Em suas ações e por meio da dinâmica que institui, a professora trabalha a partir de outros modos de conceber a criança, construindo práticas educativas diferenciadas, abdicando de uma posição de poder, instaurando diferentes modos de ensinar e, assim, afetando a forma com que as crianças aprendem. A professora potencializa as ideias, os desejos de seus alunos, e com estes caminha para o desenvolvimento de seu trabalho, possibilitando que as atividades sejam criadas, (re)elaboradas conjuntamente com as crianças. Ao contrário do que temos encontrado em muitas turmas, no trabalho de campo registramos as crianças em seus conflitos entre o saber e o fazer, e a professora dizendo faz uma linha aqui como seu amigo, recorta aqui, você não quer enfeitar com alguma coisa?, o que podemos por aqui para prender? Assim, os trabalhos de cada criança iam tomando uma forma única e ao mesmo tempo as crianças em suas tentativas também construíam e participavam sem dizer não sei fazer, não sei desenhar, não sei pintar.

Contemporaneamente, podemos observar instituições de Educação Infantil que são povoadas por brinquedos (bolas, bonecas, carrinhos, encaixes, quebracabeças, brinquedos coloridos); com certeza, eles são fundamentais e instigadores. Mas, também nelas existe uma série de outras possibilidades que, muitas vezes, permanecem invisíveis e que são extremamente potentes para as construções imaginativas.

O espaço e os objetos que o constituem instigam pelo que convidam. Às vezes convidam ao deslocamento, às vezes à observação [...] são possibilidades de descobrir nos objetos sentidos novos, pelo que eles sugerem. Cabe ao educador atentar para o encontro das crianças com os objetos e os espaços. (GUIMARÃES, 2006, p. 75-76).

No cotidiano da turma acompanhada, as crianças têm oportunidade de lidar com o espaço e com materiais em processo de transformação constante. Papéis, tecidos, barbantes, feijões se modificam e se constituem em campos para a 
imaginação, em brinquedos, em obras de arte. Porém para que estas possibilidades se materializem, o trabalho pedagógico é essencial. É imprescindível que a professora assuma sua posição de mediadora, dê ideias, ajude as crianças a executarem as que elas têm; ou seja, que não trate a imaginação como um processo espontâneo. Não espera que elas tenham ideias para fazer um acampamento, embora possamos conjecturar que se esta proposta partisse das crianças, ela a legitimaria. Não espera que elas solicitem a retomada das produções do painel, do farol, das fantasias para a história produzida. Ao fazê-lo, parece-nos que aposta nas possibilidades de criações inteiramente novas e não no mero acúmulo de experiências. Colocam-se em jogo novas ideias, novos materiais, novos usos para os mesmos materiais, resultando destes processos obras singulares. Basta aqui lembrarmos que com recortes de papeis em certo dia, faz-se sopa ou arroz e, em outro, coroas e vestidos. Isso não significa que uma produção seja mais sofisticada que a outra ou que, nas próximas experiências, novos produtos mais complexos sejam criados. No campo da imaginação os caminhos não são/não devem ser plenamente planejados. Em outras circunstâncias, por razões diversas, é possível que algumas crianças queiram “cortar, só!”, e que estas explorações técnicooperacionais sejam a base para novas explorações e produções imaginativas.

Para finalizar, ressaltamos que o fato de não seguir uma rotina rígida não significa que o trabalho da professora acompanhada seja aleatório e/ou pouco fundamentado teoricamente. Ao contrário, para realizá-lo, é imprescindível uma formação sólida, que propicie recursos permanentes para pensar, refletir, contextualizar e, acima de tudo, ressignificar sua prática. É preciso, também, que tenha seu trabalho legitimado, institucionalmente e pelos pais das crianças. Sendo assim - e coerentemente com a matriz teórica assumida no presente artigo - a originalidade e criatividade do trabalho desta professora não é obra individual. Cada ato docente está permeado pelas oportunidades de formação que teve (inicial, continuada e em outras circunstâncias em que teve acesso a bens culturais) e pelas condições de trabalho em que se encontra. 


\section{referências}

ABRAMOWICZ, Anete; Levcovitz, D.; Rodrigues, T. C. Infâncias em Educação Infantil. Pro-Posições (UNICAMP. Impresso), v. 20, p. 1-15, 2009.

ARCE, Alessandra Martins. O Referencial Curricular Nacional para a Educação Infantil e o espontaneísmo: (re) colocando o ensino como eixo norteador do trabalho pedagógico com crianças de 4 a 6 anos. In: Arce, A. M., L. M. (Org.). Quem tem medo de ensinar na Educação Infantil? Em defesa do ato de ensinar. 1. ed. Campinas: Alínea, v. 01, p. 13-36, 2007.

BRASIL. Ministério da Educação e do Desporto. Referencial Curricular Nacional para a Educação Infantil. Brasília: MEC, 1998. (v. 1, 2 e 3).

BRASIL, Ministério da Educação. Diretrizes Curriculares Nacionais para a Educação Infantil. Brasília: MEC, 2009.

BRASIL, Ministério da Educação. Secretaria de Educação Básica. Brinquedos e brincadeiras de creches. Manual de orientação pedagógica. Brasília, 2012. Disponível em: <portal.mec.gov.br/dmdocuments/publicacao_brinquedo_e_brincadeiras_compl eta.pdf>

CARVALHO, Maria Thereza Ferreira de. Artes na Educação Infantil: um estudo das práticas pedagógicas do professor de escola pública. Dissertação de Mestrado em Educação. Pontifícia Universidade Católica de São Paulo, São Paulo, 2010. https://tede2.pucsp.br/handle/handle/10798

CORSINO, Patrícia. Linguagem na Educação Infantil: as brincadeiras com as palavras e as palavras como brincadeiras. O cotidiano na educação infantil. Ministério da Educação/ Educação à distância. p 28- 45, nov. 2006.

CRUZ, Maira Nazaré. Imaginação, conhecimento e linguagem: uma análise de suas relações numa perspectiva histórico-cultural do desenvolvimento humano. Tese de Doutorado, Universidade Estadual de Campinas, Campinas, 2002.

FARIA, Ana Lucia Goulart; Santiago, F.; Barreto, A.; Santos, S.E. Por uma educação infantil emancipatória: infâncias, adultos e adultas descolonizadas /os. Nuevamérica (Buenos Aires). v. 138, p. 35-39, 2013.

GERMANOS, Ana Paula R. Desvendando o jogo: os dizeres de professores sobre o brincar no trabalho pedagógico. Dissertação de Mestrado em Educação. Unimep/Piracicaba, 2001.

GÓES, Maria Cecília Rafael de. A formação do indivíduo nas relações sociais: Contribuições teóricas de Lev S. Vigotski e Pierre Janet. Educação e Sociedade, $\mathrm{n}^{\mathrm{o}}$ 71, p116-131. São Paulo, 2000.

GUIMARÃES, Daniela de O. Educação Infantil: espaços e experiências. O cotidiano na educação infantil. Ministério da Educação/ Educação à distância, 2006.

KRAMER, Sônia. Infância e Educação Infantil: reflexões e lições. Em: LEITE, C.D.P.; OLIVEIRA, M.B.L.; SALLES, L.M.F. (Orgs) Educação, psicologia $e$ contemporaneidade: novas formas de olhar a escola. Taubaté: Cabral Editora Universitária, 2000.

LEITE, Adriana Regina Isler Pereira. O lugar do imaginário na prática pedagógica da Educação Infantil. Tese de Doutorado em Educação. Unimep/Piracicaba, 2004.

LEITE, César Donizetti Pereira. Infância, cinema e formação: contornos de 
modulações, subjetividades e singularidades. ETD. Educação Temática Digital, v. 14, p. 314-331, 2012.

NEITZEL, Scheila Thaís Lüdke. Brincadeira e aprendizagem: concepções docentes na educação infantil. Dissertação de Mestrado na Faculdade de Educação. UFRGS, 2012. http:/ / hdl.handle.net/10183/61753.

PALHARES, M.S.; Martinez, C.M.S. A educação infantil - uma questão para o debate. In: Faria, A.L.G.; Palhares, M.S. (Orgs.) Educação Infantil pós LDB: Rumos e desafios. Campinas: Autores Associados/FE-UNICAMP; São Carlos: Ed. UFSCAR; Florianópolis: Ed. UFSC,1999.

PIRES, Carolina Teixeira. O essencial no ser e a poesia dos sentidos e dos significados: reflexões sobre arte e educação em contextos destinados à primeira infância. Dissertação de Mestrado na Escola de Comunicações e Artes. USP, São Paulo, 2012. http:/ / www.teses.usp.br/teses/disponiveis/27/27160/tde-17052013-1554

PONTES, Gilvânia Maurício Dias de. Arte na educação da infância: saberes e práticas da dimensão estética. Tese de Doutorado. Universidade Federal do Rio Grande do Sul. Faculdade de Educação. Programa de Pós-Graduação em Educação. 2013. http:/ / hdl.handle.net/10183/70604.

ROCHA, Maria Sílvia Pinto de Moura Librandi da. Não brinco mais - a descontrução do brincar no cotidiano educacional. 2. ed. Ijuí: Ed. Unijuí, 2005.

ROCHA, Maria Sílvia Pinto de Moura Librandi da. Imaginar, calcular, ressignificar: articulações entre imaginação e cognição em práticas pedagógicas. Revista de Educação. PUC-Camp., Campinas, v. 19, n. 3, p. 227-237, set./dez., 2014.

SMOLKA, Ana Luiza Bustamante. Comentários. In: Vigotski, L. S. Imaginação e criação na infância. São Paulo: Ática, p.10-59, 2009. Disponível em: <http://hdl.handle.net/10183/70604> Acesso: 20 fev. 2017.

TERCIOTTI, A.H.M.M. Da orientação oficial a prática efetiva: O brincar de ações e ideias sobre o brincar na formação continuada do Educador Infantil. Dissertação de Mestrado em Educação. Unimep/Piracicaba, 2001.

VYGOTSKY, Lev Semionovitch. La imaginación y el arte en la infancia. (trad.) Cidade do México: Hispânicas. (Original de 1930), 1987a.

VYGOTSKY, Lev Semionovitch. Thinking and Speech. Problems of General Psichology. In Rieber, R. \& Carton, A. (eds). Collected works of L. S. Vygotsky. New York, Plenum Press, 1987b.

VYGOTSKY, Lev Semionovitch. A formação social da mente. São Paulo: Martins Fontes, 1989. 